\title{
COMPARATIVE ANALYSIS OF ALGORITHMS BEING USED FOR MEASUREMENT OF DISCHARGE THROUGH RADIAL GATES OF CANAL CONVEYANCE SYSTEM
}

\author{
Rana Vinodkumar Mohansinh \\ Assistant Professor, Adani Institute of Infrastructure Engineering (AIIE), \\ Ahmedabad, Gujarat, India
}

\begin{abstract}
The efficiency at field level is in large part measured in terms of the evenness of depth of moisture of the soil, which is directly related to the constant delivery of discharge. The deficiency in operation of networks may be due to incorrect measurement of discharge passing through the Check Structure. For measuring the discharge through gate, the value of Coefficient of Discharge $C_{d}$ is one of the important factors. The value of $\mathbf{C}_{d}$ for any gate can be assessed either by continuous observation at site for long duration or by regression analysis or by developing a laboratory model.

The discharge algorithms accurately represent the complete discharge characteristics for the range of water levels and radial gate geometry normally encountered at canal radial gate check structures. The primary disadvantage of the discharge algorithms is their complexity
\end{abstract}

Keywords: gate algorithm, coefficient of discharge, radial gate

\section{INTRODUCTION}

In many parts of the World, irrigation systems are normally performing well below their potential and it is mainly attributed to the improper or ineffective operation of control structure. One measure used for assessing the performance of an irrigation system is based on the ratio of water volume released from the sources to that actually applied to the crop at field. Many of the problems associated with these irrigation schemes are linked at least partially to ineffective operation of the water distribution systems. The efficiency of the Major network depends on the operation of the input gate and the check gates, which are along the main canals. The efficiency of the Minor network depends upon the accuracy of the discharge delivered by the main canal as well as the operation of the regulation structures within the minor network itself. The efficiency at field level is in large part measured in terms of the evenness of depth of moisture of the soil, which is directly related to the constant delivery of discharge. The deficiency in operation of networks may be due to incorrect measurement of discharge passing through the Check Structure. Thus the one of the objective of the control system is how to operate the canal to maintain the prescribed discharge in pools of canal. The automatic control can greatly enhance the efficiency of the operation of open channel water conveyance system due to greater flexibility, reliability and safety and will have a minimum operational waste reducing cost of operation when compared to manual operation. In the canal automation system, accurate gate head discharge equation to assess the discharge passing below each gate of the check structure i.e., the check structure to serve as a flow measuring device or to set the appropriate gate opening for a desired discharge by knowing the water level on upstream and downstream of the check structure i.e. the check structure to serve as a flow control structure.

For measuring the discharge through gate, the value of Coefficient of Discharge $C_{d}$ is one of the important factors. The value of $C_{d}$ for any gate can be assessed either by continuous observation at site for long duration or by regression analysis or by developing a laboratory model.

\section{GATE STROKING ALGORITHM}

The change from one discharge to another in open channel flow always creates a disturbance in water surface elevation. Since pool boundaries are usually gates, the technique of water surface control is called Gate Stroking. Gate stroking is series of continuous or discontinuous gate motions which produce a desired water surface profile in a canal. The Coefficient of Discharge $C_{d}$ is calculated based on regression analysis. For calculation of required opening to pass the required discharge through gate 
the difference of depth at the upstream and downstream of the check structure is used along with the value of $\mathrm{C}_{\mathrm{d}}$ based on regression analysis.

\section{DISCHARGE ALGORITHM OF CANAL RADIAL GATE}

In Discharge Algorithm of Canal Radial Gate i.e. RADGATE, the value of $C_{d}$ is based on a 1:6 canal radial gate model. For calculation of required gate opening to pass the required discharge the Metzler's equation is used. In Metzler's equation only depth at the upstream of the check structure is used along with the value of $C_{d}$ to calculate required gate opening. The value of $\mathrm{C}_{\mathrm{d}}$ is calculated for two different flow condition i.e. free flow condition and submerged flow condition but the effect of downstream depth is already considered in calculation of $\mathrm{C}_{\mathrm{d}}$.

For comparative study of these two discharge algorithms, two canal pools with three check structures of canal is selected and schematic is shown vide Fig.1.

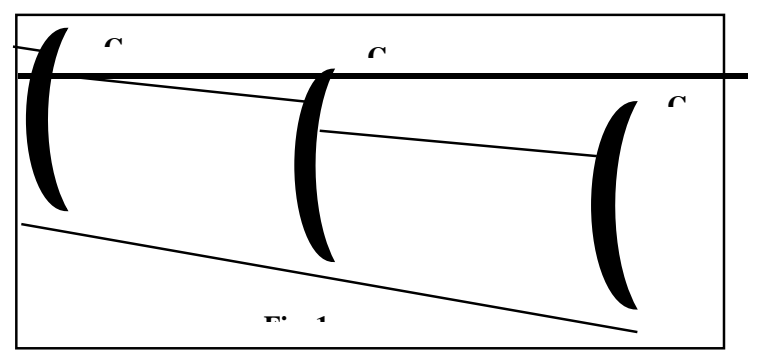

The middle check structure i.e. CR-2 is selected to compare the results because on upstream and downstream of this check structure, the conditions are fully controlled.

For analysis, the variation of discharge in pools is taken from 75 cumecs to 900 cumecs. The transient analysis in these pools is done with the help of Unsteady State Model [Acharya (1994)]. The depths at the upstream and downstream of these check structures are based on transient analysis and the same are used for calculation of required gate openings in both the discharge algorithm of gates as per the concept of mass conservation.

\begin{tabular}{|c|c|c|c|}
\hline \multirow{2}{*}{$\begin{array}{l}\text { Sr. } \\
\text { No. }\end{array}$} & \multirow{2}{*}{$\begin{array}{l}\text { Discharge } \\
\text { (Cumecs) }\end{array}$} & \multicolumn{2}{|c|}{$\begin{array}{c}\text { Option "A" } \\
\text { (Gate Stroking Algorithm) }\end{array}$} \\
\hline & & $\begin{array}{c}\text { Gate } \\
\text { Opening } \\
\text { (cm) }\end{array}$ & $\mathbf{C}_{\mathbf{d}}$ \\
\hline 1 & 75 & 23.20 & 0.699 \\
\hline 2 & 100 & 31.10 & 0.696 \\
\hline 3 & 150 & 47.10 & 0.689 \\
\hline 4 & 200 & 63.50 & 0.683 \\
\hline 5 & 300 & 97.30 & 0.671 \\
\hline
\end{tabular}

\begin{tabular}{|r|r|r|r|}
6 & 400 & 133.00 & 0.659 \\
\hline 7 & 500 & 171.00 & 0.650 \\
\hline 8 & 600 & 211.70 & 0.644 \\
\hline 9 & 700 & 255.00 & 0.643 \\
\hline 10 & 800 & 301.00 & 0.647 \\
\hline 11 & 900 & 349.20 & 0.657 \\
\hline
\end{tabular}

\begin{tabular}{|c|c|c|c|}
\hline \multirow[b]{2}{*}{$\begin{array}{l}\text { Sr. } \\
\text { No. }\end{array}$} & \multirow[b]{2}{*}{$\begin{array}{l}\text { Discharge } \\
\text { (Cumecs) }\end{array}$} & \multicolumn{2}{|c|}{ Option "B" (RADGATE) } \\
\hline & & $\begin{array}{c}\text { Gate } \\
\text { Opening } \\
(\mathrm{cm}) \\
\end{array}$ & $\mathbf{C}_{\mathbf{d}}$ \\
\hline 1 & 75 & 15.90 & 0.665 \\
\hline 2 & 100 & 20.10 & 0.702 \\
\hline 3 & 150 & 31.20 & 0.679 \\
\hline 4 & 200 & 43.30 & 0.653 \\
\hline 5 & 300 & 67.60 & 0.627 \\
\hline 6 & 400 & 91.20 & 0.621 \\
\hline 7 & 500 & 113.30 & 0.626 \\
\hline 8 & 600 & 133.60 & 0.638 \\
\hline 9 & 700 & 151.80 & 0.656 \\
\hline 10 & 800 & 167.50 & 0.681 \\
\hline 11 & 900 & 180.00 & 0.715 \\
\hline
\end{tabular}

\begin{tabular}{|r|r|r|r|}
\hline \multirow{2}{*}{$\begin{array}{r}\text { Sr. } \\
\text { No. }\end{array}$} & \multirow{2}{*}{$\begin{array}{c}\text { Discharge } \\
\text { (Cumecs) }\end{array}$} & \multicolumn{2}{|c|}{ Difference } \\
\cline { 3 - 4 } & & \multicolumn{1}{|c|}{ GO $(\mathbf{c m})$} & \multicolumn{1}{c|}{$\mathbf{C}_{\boldsymbol{d}}$} \\
\hline 1 & 75 & 7.30 & 0.034 \\
\hline 2 & 100 & 11.00 & -0.006 \\
\hline 3 & 150 & 15.90 & 0.010 \\
\hline 4 & 200 & 20.20 & 0.030 \\
\hline 5 & 300 & 29.70 & 0.044 \\
\hline 6 & 400 & 41.80 & 0.038 \\
\hline 7 & 500 & 57.70 & 0.024 \\
\hline 8 & 600 & 78.10 & 0.006 \\
\hline 9 & 700 & 103.20 & -0.013 \\
\hline 10 & 800 & 133.50 & -0.034 \\
\hline 11 & 900 & 169.20 & -0.058 \\
\hline
\end{tabular}

The results of these analysis is presented graphically vide Figure-2.

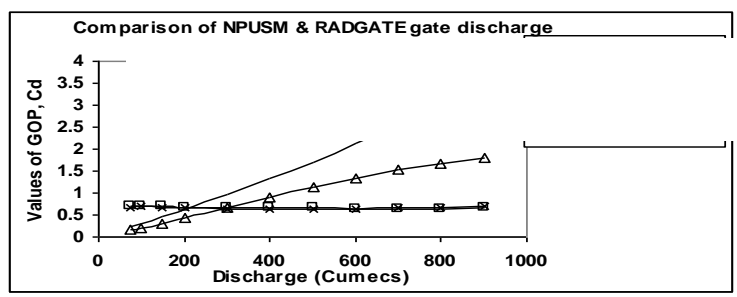

Figure-2 Comparison of Gate Stroking Algorithm and RADGATE Algorithm

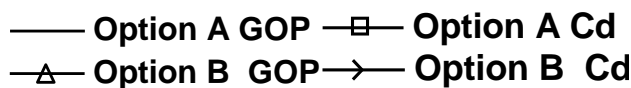




\section{International Journal of Engineering Applied Sciences and Technology, 2020 \\ Vol. 5, Issue 8, ISSN No. 2455-2143, Pages 255-257 \\ Published Online December 2020 in IJEAST (http://www.ijeast.com)}

\section{CONCLUSION}

From the results it is clear that the calculation of $\mathrm{C}_{\mathrm{d}}$ values in both the algorithm does not differ significantly. For all the variation of discharges the values of $C_{d}$ in both the gate discharge algorithm remains almost same. But it is observed that the required gate openings (GOP) in both the algorithm differs for all discharge variations. The gate opening GOP varies from $7.3 \mathrm{~cm}$ to $169.2 \mathrm{~cm}$ and $\mathrm{C}_{\mathrm{d}}$ varies from 0.005 to 0.04 . The variation of GOP increases as discharge increases. But the difference of $\mathrm{Cd}$ value increases upto $40 \%$ variation of Maximum discharge i.e. 900 cumecs and for greater variation i.e. more than $40 \%$ variation of maximum discharge again it decreases. These result shows that initially at the design stage the value of $C_{d}$ can be based on regression analysis or can be based on laboratory model. After the construction of gate, the $C_{d}$ values should be fine tuned with the observation at the site. The discharge algorithms accurately represent the complete discharge characteristics for the range of water levels and radial gate geometry normally encountered at canal radial gate check structures. The primary disadvantage of the discharge algorithms is their complexity. Many equations are necessary to achieve the high degree of accuracy. The discharge algorithms listed above are based on the standard hardrubber-bar gate lip seal design. The algorithms, correctly applied, have the capability of being as accurate as any measuring device or procedure available to measure the discharge in small or large canal systems. As a result, a direct benefit is provided for canal operators who control canal systems manually or by remote manual/automatic control systems. The installation of costly Parshall flumes, weirs, acoustic velocity meters, and many canalside turnout meters could be eliminated providing an economic benefit to the project.

\section{REFERENCES}

Falvey H.T., Luning P.C,(1979). “Gate Stroking”, Report No.REC-ERC-79-7, Bureau of

Reclamation, United States Department of the

Interior, Denver, Colorado, USA.

Buyalski, C.P.(1983), "Discharge Algorithms for Canal Radial Gates, " Report No.83(9), Bureau of Reclamation Engineering and Research Centre, Denver, Colorado, USA.

Acharya, K.D.(1994), "Development of Downstream Control Algorithm, " Ph.D. Thesis, Indian Institute of Technology (Bombay), Mumbai.
Rana, V.M.(2001), "Local Canal Controller Algorithm," Ph.D. Thesis, Indian Institute of Technology (Bombay), Mumbai. 